\title{
Corrigendum: The revenge of the words: On language's historical and autonomous being and its effects on 'secularisation'
}

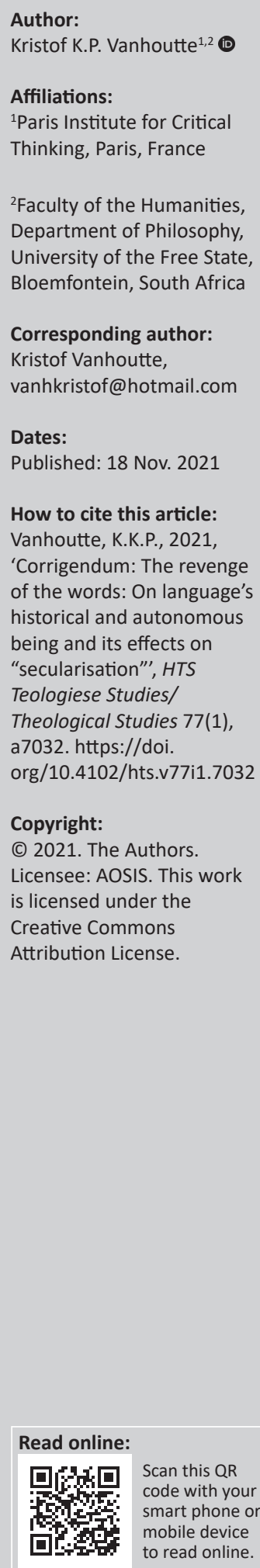

In the version of this article initially published, Vanhoutte, K.K.P., 2020, "The revenge of the words: On language's historical and autonomous being and its effects on "secularisation"”, HTS Teologiese Studies/ Theological Studies 76(2), a6076. https://doi.org/10.4102/hts.v76i2.6076, the author's second affiliation was given incorrectly in the 'Affiliation' section. The correct affiliation should be 'Faculty of the Humanities, Department of Philosophy, University of the Free State, Bloemfontein, South Africa' instead of 'Faculty of Philosophy, University of the Free State, Bloemfontein, South Africa'.

This correction does not alter the study's findings of significance or overall interpretation of the study's results. The author apologises for any inconvenience caused. 